\title{
A LEI N. 9.474/97 E A DEFINIÇÃO AMPLIADA DE REFUGIADO: BREVES CONSIDERAÇÕES
}

\author{
Guilherme Assis de Almeida \\ Aluno de Pós-Graduação em Filosofia do \\ Direito pela USP
}

Resumo:

O autor analisa de forma cronológica a cvolução dos posicionamentos brasileiros dentro do Direito Internacional quanto à questão dos refugiados, passando pelo processo de definição do conceito do que viria a ser o status de refugiado para o Direito brasileiro e pela análise dos tratados e compromissos internacionais assumidos e ratificados pelo Governo brasileiro.

\begin{abstract}
:
The author analyzes in a chronological way the evolution of the Brazilian positionings whithin the International Law related to the refugees' subject, going through the process of definition of the concept of the onc that would come be the refugee's status for the Brazilian Law and by the analysis of the agreements and international commitments assumed and ratified by the Brazilian Government.
\end{abstract}

Unitermos: Direito Internacional, proteção internacional dos Direitos Humanos, contexto histórico-jurídico brasileiro.

\section{Histórico da Lei n. 9.474/97}

A partir de 22 de julho de 1997. o Brasil incorpora, definitivamente, ao seu ordenamento jurídico a Convenção sobre o Estatuto do Refugiado de 1951. A Convenção de 1951 é um dos primeiros Tratados Internacionais de Direitos Humanos. Mais precisamente, é o segundo. Visto que, o primeiro Tratado Internacional de Direitos Humanos é a Convenção contra o Genocídio, de 1948. 
A Lei brasileira n. 9.474/97 é a primeira lei do ordenamento jurídico brasileiro a implementar ${ }^{1}$ um Tratado de Direito Internacional dos Direitos Humanos. A elaboração e entrada em vigor da Lei n. 9.474/97 é um verdadeiro marco na trajetória de comprometimento do Brasil com a temática dos refugiados. Esta trajetória inicia-se, em 1952, com o reconhecimento da Convenção sobre 0 Estatuto do Refugiado, de 1951, e culmina com a promulgação da Lei n. 9.474/97.

A seguir farei um sintético histórico do Direito Internacional dos refugiados, no Brasil, até sua definitiva incorporação ao Direito brasileiro, fato que se deu em 22 de julho de 1997

15 de julho de 1952: Brasil assina a Convenção sobre o Estatuto de Refugiado de 1951.

28 de janeiro de 1961: Decreto n. 50.215 promulga a Convenção sobre o Estatuto do Refugiado de 1951, no ordenamento jurídico brasileiro. É feita uma "reserva geográfica" ou seja, o Brasil só aceita refugiados vindos do continente europeu.

08 de agosto de1972: Decreto n. 70.946 promulga o Protocolo de 1967. que passa a integrar o ordenamento jurídico brasileiro.

1977: Primeira missão do Alto Comissariado das Nações Unidas ACNUR no Brasil (esta missão instala-se na cidade do Rio de Janeiro). Nesta época, em plena ditadura militar, a atividade do ACNUR limita-se a reassentar, em um terceiro país de asilo, buscadores de asilo vindos de países da América do Sul: Chile, Argentina, Uruguai e Paraguai.

1. Importante precisar o exato significado do verbo implementar, neste contexto. Esclareça-se que o Brasil ratifica e promulga a Convenção de 1951, no ano de 1961.Todavia, a questão dos refugiados requer, principalmente, a realizaçāo de duas tarefas: 1. a elegibilidade dos casos individuais, e 2. a elaboração de políticas públicas que visem à integração local dos refugiados. Tais tarefas foram realizadas pelo ACNUR (Alto Comissariado das Nações Unidas para Refugiados) até a promulgação da Lei n. 9.474/ 97.

A partir desta lei, o Brasil: a. estabelece critérios próprios para a concessão do estatuto de refugiado; bem como, um "procedimento de elegibilidade"; b. cria, no âmbito da Administração Pública Federal, o Comitê Nacional para Refugiados (Conare) que é responsável pela elegibilidade dos casos individuais e pela elaboração de políticas públicas que facilitem a integração local.

É a primeira lei brasileira a criar uma estrutura na Administração Pública e um procedimento próprio para implementar um Tratado de Direito Internacional dos Direitos Humanos. Trata-se do exercício do Direito Cosmopolítico, como definido por Kant. 
1979-80: 150 (cento e cinqüenta) vietnamitas são acolhidos. Não lhes é concedido o status de refugiado (por causa da reserva geográfica), mas um estatuto migratório alternativo lhes é dado.

1982: Presença do ACNUR enquanto organização internacional é oficialmente reconhecida pelo Governo brasileiro.

1986: Brasil acolhe 50 (cinqüenta) famílias Bahai's, aproximadamente 200 (duzentas) pessoas, perseguidas no Irã, por razões religiosas. Por não poderem receber o status de refugiado (em razão da reserva geográfica), são reconhecidos como asilados.

1989: Escritório do ACNUR é transferido para Brasília. No final deste ano (1989), levanta-se a cláusula da reserva geográfica.

1992-1994: Brasil acolhe cerca de 1,2 mil angolanos que são obrigados a deixar seu país logo após o final das eleições. Apesar de não serem refugiados, de acordo com a definição clássica de 1951 (fundado temor de perseguição em razão de: raça, religião, nacionalidade, filiação a grupo social ou opinião política), o Governo brasileiro concede-lhes o status de refugiado, aplicando a Declaração de Cartagena que prevê a concessão do status de refugiado devido à "grave e generalizada violação de direitos humanos" (guerra civil em Angola).

Maio de 1996: projeto de lei que estabelece a incorporação da Convenção de 1951 ao Direito brasileiro é enviado ao Congresso Nacional juntamente com o Plano Nacional de Direitos Humanos.

22 de julho de 1997: A Lei n. 9.474 que implementa a Convenção sobre o Estatuto do Refugiado de 1951 ao Direito brasileiro é sancionada e promulgada pelo presidente da República.

Depois da promulgação da Lei n. 9.474/97, existem algumas datas que merecem ser lembradas:

07 de setembro de 1998: Na festa comemorativa dos Direitos Humanos toma posse a Coordenadoria do Conare (Comitê Nacional para os Refugiados) que tinha como presidente a dra. Sandra Valle (Secretaria Nacional de Justiça do Ministério da Justiça) a atual presidente é a dra. Elisabeth Sussekind e como coordenadora a sra. Nara Moreira da Silva. O Conare é o órgão do Governo brasileiro responsável pela elegibilidade dos "casos individuais" bem como da elaboração das políticas públicas para os refugiados. O Conare é formado por 
representantes do: Ministério da Justiça (onde está sediado), Ministério das Relações Exteriores, Ministério da Educação, Ministério do Trabalho, Ministério da Saúde, Departamento da Polícia Federal, Organização Não-Governamental ligada à temática dos Refugiados (atualmente a Cáritas Brasileira) e o ACNUR, como membro convidado, com voz, mas sem voto.

26 de maio de 1999: A reunião plenária do Conare aprova a resolução de n. 06 que regulamenta a emissão do protocolo para o solicitante de refúgio. 0 protocolo dá ao solicitante a autorização para a estadia provisória no país, até que seu pedido seja definitivamente julgado, e também lhe possibilita requerer a carteira de trabalho provisória que permite ao solicitante trabalhar, de forma regular, em território brasileiro. O presidente em exercício do Conare, Luiz Paulo Telles Barreto, apresenta proposta do Governo do Paraná de reassentar 10 (dez) famílias de pessoas afetadas pelo conflito na ex-Iugoslávia. A proposta foi aprovada por unanimidade.

10 de agosto de 1999: O ministro da Justiça José Carlos Dias e o representante regional do ACNUR, para o sul da América do Sul, Guilherme da Cunha assinam o acordo para o reassentamento de pessoas afetadas pelo conflito na ex-Iugoslávia. Durante a solenidade de assinatura deste acordo o ministro José Carlos Dias manifestou o interesse do governo brasileiro em assinar um novo acordo de reassentamento no qual os beneficiários seriam pessoas afetadas pelo conflito em Angola.

A assinatura deste acordo é um fato inédito e demonstra, mais uma vez, o grau de comprometimento do Governo brasileiro com a questão dos refugiados.

II. A definição ampliada de refugiado

A definição clássica de refugiado é a que consta na Convenção Relativa ao Estatuto dos Refugiados de 1951. Estabelece o seu art. $1^{\circ}$ inciso A, $\S 2^{0}$.

"A. Para os fins da presente Convenção, o termo 'refugiado' aplicarse-á a qualquer pessoa:

(2) Que, em conseqüência de acontecimentos ocorridos antes de 01 de janeiro de 1951, e receando com razão ser perseguida em virtude da sua raça, religião, nacionalidade, filiação em certo grupo social ou das suas opiniōes 
políticas, se encontre fora do pais de que tem a nacionalidade e não possa ou, em virtude daquele receio, não queira pedir a proteção daquele país; ou que, se não tiver nacionalidade e estiver fora do país no qual tinha a sua residência habitual após aqueles acontecimentos, não possa ou, em virtude do dito receio, a ele não queira voltar.

Por esta definição é refugiado aquele que, em virtude das razões acima elencadas, sofre, de forma individual, uma perseguição.

Diz-se que a pessoa sofre uma perseguição quando sua vida e/ou sua liberdade estão sendo ameaçadas. Caso as razões determinantes desta perseguição sejam: raça, religião, nacionalidade, filiação em determinado grupo social ou opinião política, a pessoa será considerada um refugiado, consoante a definição clássica.

Como já dito, anteriormente, a Convenção Relativa ao Estatuto dos Refugiados, de 1951, é o segundo Tratado de Direito Internacional dos Direitos Humanos (o primeiro é a Convenção contra o Genocídio, de 1948). A definição, nela constante, visa responder à situação de inimaginável mobilidade humana provocada pela Segunda Guerra Mundial. À época, não se previa que o problema dos refugiados tornar-se-ia crônico. Tanto é que a Convenção de 1951 possui uma limitação temporal. Estabelece como data limite o dia $1^{\circ}$ de janeiro de 1951 . Ou seja, serão reconhecidos como refugiados aqueles que foram perseguidos em consequência de acontecimentos ocorridos antes de $1^{0}$ de janeiro de 1951. (Convenção de 1951, art. $1^{\circ}$ : inciso A, $\S 2^{\circ}$ ). ${ }^{2}$

\section{Afirma Diego López Garrido:}

"El Convenio de Ginebra de 1951 estaba pensado para una situación posterior a la Segunda Guerra Mundial de división de nuestro continente. Se trataba de facilitar la venida a Europa occidental de quienes huían de Europa oriental. Personas com un bagaje cultural similar y también com unas similitudes étnicas obvias.

2. A limitação temporal estabelecida pela Convenção de 1951 foi superada pelo Protocolo de 1967. 
Tal esquema estaba pensado para tratar un tipo de peticionário de asilo que podia individualizarse y tratarse caso por caso, porque no era un asilo masivo" (EI derecho de asilo, Editorial Trota, $1^{a}$ edição, 1991, p. 121).

A concepção ampliada de refugiado surgiu na Convenção da OUA (Organização da Unidade Africana), pela qual se regulam os aspectos específicos do problema dos refugiados na África, aprovada em 10 de setembro de 1969, entrando em vigor em 20 de junho de 1974 . Estabelece a Convenção, no seu art. $1^{\circ}$, inciso 2 :

"2. O termo 'refugiado' aplicar-se-á também a toda pessoa que, por causa de uma agressão exterior, uma ocupação ou uma dominação estrangeira, ou de acontecimentos que perturbem gravemente a ordem pública em uma parte ou na totalidade de seu país de origem, ou do país de sua nacionalidade, está obrigada a abandonar sua residência habitual para buscar refúgio em outro lugar fora do seu país de origem ou do país de sua nacionalidade"

A palavra asilo significa a-sylum. Sylum, palavra grega, é violência, e o prefixo "A" é um prefixo negativo. Portanto asilo significa "não-violência"

A definição ampliada de refugiado coaduna-se pois, perfeitamente, com o significado original da palavra asilo. A idéia é oferecer à pessoa, vítima de uma violência, a possibilidade de encontrar uma proteção. Um lugar seguro para viver e gozar sua liberdade. Essencialmente, o "buscador de asilo" 3 é sempre alguém que está fugindo de uma situação insuportável de violência. Seja pela definição clássica ou pela definição ampliada.

A definição clássica está focada nos acontecimentos pós-45 e é uma definição numerus clausus. Nas suas cinco razões de perseguição há espaço possível para interpretação, fora isto não.

Já a definição ampliada da Convenção da OUA busca descrever uma situação coletiva onde as pessoas individualmente estejam ameaçadas, sendo

3. No Direito Internacional dos refugiados existem dois termos genéricos para designar a pessoa que deixou sua terra natal em busca de asilo: asylum seeker e refugee. Traduzi asylum seeker como c buscador de asilo. Este pode estar em duas situaçōes: enquanto mero buscador, deixou seu país dr origem e está num estrangeiro em busca de proteção, e como solicitante de refúgio, já iniciou । procedimento jurídico atinente à concessão do Estatuto de Refugiado. Refugiado é aquele a quem fo concedido o status de refugiado. 
motivada pelos acontecimentos que têm lugar na África desde 1956. ${ }^{4}$ Deste modo, esta definição é dita ampliada, pois ela consegue açambarcar um número muito maior de possibilidades, nas quais o ser humano encontre-se vulnerável e necessitado de proteção.

No caso da definição ampliada, quando da análise do caso individual, dá-se uma importância maior à análise da situação política e institucional do país e sua relação com a situação individual do solicitante, procurando avaliar até que ponto a vida e a liberdade do solicitante encontram-se ameaçadas pela "grave e generalizada" violação dos Direitos Humanos. Veja o caso de Serra Leoa, um minúsculo país africano, vivendo uma sanguinária e brutal guerra civil (nos últimos três anos gerou 350 mil refugiados), qualquer habitante de seu território corre o risco de ser atingido pela violência ali imperante. Quanto à definição clássica da Convenção de 1951, a análise do caso individual é focada, inicialmente, no histórico do indivíduo e, num segundo momento, na relação deste histórico com a situação do país.

A definição ampliada de refugiado surge, no continente americano, na Declaração de Cartagena, de 1984. Esta declaração é o resultado de um colóquio em Cartagena de Índias, na Colômbia, realizado como reação à crise de refugiados da América Central, ocorrida no início dos anos 80.

Na terceira conclusão da Declaração de Cartagena estabelece-se:

Terceira. "Reiterar que, em vista da experiência tida em função da afluência massiva de refugiados na área centroamericana, faz-se necessário

4. 1956 - A guerra pela independència da Argélia provocou a maior onda de refugiados na história moderna da África, ocasionando a fuga de dezenas de milhares de pessoas para a Tunisia e para o Marrocos. O ACNUR interveio em 1957 e, cinco anos mais tarde, ajudou a repatriar $260 \mathrm{mil}$ argelinos.

1958 Um milhão de habitantes da Guiné tiveram de se exilar depois que o país se independentizou da França, mas logo as tensōes se exacerbaram com as antigas leis coloniais.

1960 - O movimento anticolonial espalhou-se pelo centro e sul da África, provocando a difusão de movimentos populares por toda a regiāo.

1962 - O ACNUR abre o seu primeiro escritório em Burundi, em resposta à crise regional.

1966 Um êxodo começa quando a colônia africana de Portugal, Moçambique, começa a pressionar para obter sua independência, atitude que logo seguiram outras colônias portuguesas: Angola e Guiné-Bissau.

1969 Ao multiplicar-se o número de refugiados no continente, a Organização para Unidade Africana aprova a Convenção reguladora dos problemas dos refugiados africanos. 
encarar a extensão do conceito de refugiado, tendo-se em conta, no pertinente, $e$ dentro das características da situação existente na região, o precedente da Convenção da OUA (art. $1^{\circ}, \S 2^{\circ}$ ) e a doutrina utilizada nos informes da Comissão Interamericana de Direitos Humanos. Desse modo, a definição ou conceito de refugiado recomendável para sua utilização na região é aquela que além de conter os elementos da Convenção de 1951 e do Protocolo de 1967, considere também como refugiados as pessoas que fugiram de seus paises porque sua vida, segurança ou liberdade foram ameaçadas pela violência generalizada, a agressão estrangeira, os conflitos internos, a violação massiva dos direitos humanos ou outras circunstâncias que tenham perturbado gravemente a ordem pública"

O Brasil, apesar de não ter assinado a Declaração de Cartagena, aplica a definição ampliada desde 1989, ano em que é levantada a cláusula da reserva geográfica.

A Lei n. 9.474/97 expressa a definição ampliada no seu art. $1^{\circ}$ inciso III:

"Art. $1^{\circ}$ Será reconhecido como refugiado todo indivíduo que:

III - devido a grave e generalizada violação de direitos humanos, é obrigado a deixar seu país de nacionalidade para buscar refúgio em outro país.

A definição clássica e a definição ampliada estão conjugadas na lei brasileira, o que a transforma numa das leis mais avançadas e generosas do continente americano em relação à temática do Direito Internacional dos refugiados. Na América do Sul, a Argentina, apesar de não ter previsão legal da definição ampliada de refugiado, a aplica em sua prática de elegibilidade. Já o Equador, apesar da previsão legal, não a aplica.

Saliente-se que dos 107 casos decididos até o momento pelo Conare (Comitê Nacional para Refugiados), 81 foram de acordo com a definição ampliada, o que demonstra a total incorporação desta prática no Direito brasileiro.

Serra Leoa, ex-Iugoslávia, Angola. Seres humanos destes países encontraram refúgio no Brasil em 1999. Isto transforma o Brasil num espaço de distinção humanitária no continente americano.

Necessário compreender que os refugiados não estão aqui por gosto, mas por precisão. 
No Brasil encontram proteção, abrigo. Aqui podem gozar de um dos Direitos Humanos fundamentais: a liberdade. Não a liberdade de, mas a liberdade para viver com dignidade.

O homem, a mulher e a criança (infelizmente, mulheres e crianças são a grande maioria dos refugiados) quando deixam, forçosamente, sua terra natal, trazem com eles um sentimento terrivel: o ressentimento.

Todavia, este é um sentimento relacionado não com o país que lhe concedeu asilo, mas com sua história passada, vivenciada na sua terra natal.

Muitas vezes, o refugiado não consegue se livrar deste sentimento inicial. Outros o superam e passam a nutrir pelo país que lhes concedeu proteção um sentimento de gratidão. Esta gratidão produz frutos, enriquece o país acolhedor. Como o jornalista paquistanês (refugiado no Brasil) que está escrevendo um livro em "urdu" (sua língua natal) sobre o Brasil. Título do livro: Obrigado.

Creio que o Brasil tem uma desconhecida vocação para acolher aquele que precisa de proteção.

Somos um país de formação multicultural, temos uma natural tolerância em relação ao estrangeiro.

Existem hoje 900 mil estrangeiros no Brasil e 1,5 milhão de brasileiros no Exterior.

Temos hoje no Brasil 2,5 mil refugiados de mais de quarenta nacionalidades. $\mathrm{O}$ número ainda é pequeno...

Essencialmente o "buscador de asilo" é um ser humano fugindo de uma violência, seja ela de que espécie for... Muitas vezes, apresenta-se só como pessoa humana, não é cidadão de nenhum Estado, não possui nenhuma espécie de documento. $\mathrm{O}$ país que lhe concede o estatuto de refugiado lhe dá uma primeira proteção. A proteção do Direito. Vinculando-o a uma nova ordem jurídica, resgatando sua cidadania perdida. Este é o primeiro passo na recuperação da dignidade humana.

O refúgio tem um "quê" de maternal, de feminino. Guarda, proteção, abrigo. Não um maternal castrador, mas protetivo na perspectiva da autonomia. Como algumas de nossas mulheres: Fernanda Montenegro, Virgínia Rodrigues, Ruth Cardoso, Nana Caymi, Nélida Piñon, Margarida Genevois... A lista é grande. Por que não nos abrirmos para essa possibilidade? No mundo em processo de globalização, é preciso mostrar a nossa cara. De preferência, uma face humana e humanizadora. Isto é fundamental nesse novo equilíbrio de forças. 
E afinal, não fui eu, mas o presidente Fernando Henrique, que, na data nacional comemorativa dos Direitos Humanos, criou a expressão: globalização solidária.

Oxalá, Brasil!

São Paulo, janeiro de 2000. 


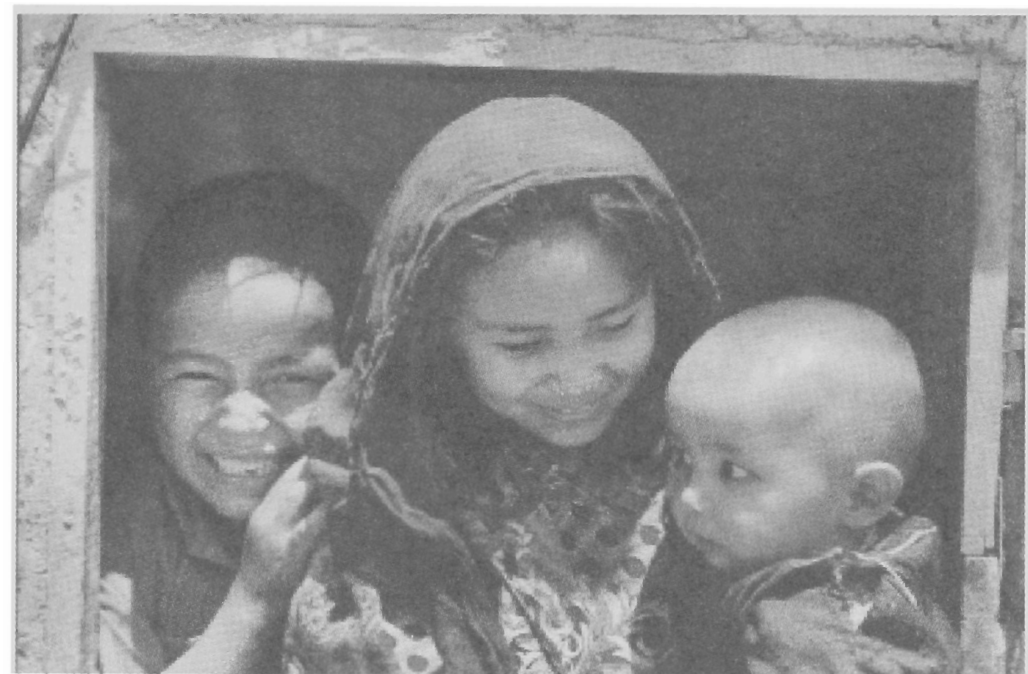

Crianças de Kabul refugiadas no Afeganistão: o mundo se sensibiliza. Foto: S. Salgado, in Helping Refugees. 